\title{
A MATERIALIZAÇÃO DO CONCEITO DE LÍNGUA EM USO NA PRODUÇÃO DE ATIVIDADES PARA O ENSINO DE PORTUGUÊS PARA ESTRANGEIROS
}

\author{
LA MATERIALIZACIÓN DEL CONCEPTO DE LENGUA EN USO EN LA \\ PRODUCCIÓN DE ACTIVIDADES PARA LA ENSEÑANZA DE PORTUGUÉS A \\ EXTRANJEROS
}

\section{THE CONCEPT OF LANGUAGE IN USE WHEN DEVELOPING ACTIVITIES FOR TEACHING PORTUGUESE TO FOREIGNERS}

RESUMO: Uma necessidade real de professores de português para estrangeiros, ao produzirem ou adaptarem atividades e materiais didáticos que se adequem a uma visão de língua como prática social, é materializar, nas atividades, o conceito e seus princípios, de modo que atenda às expectativas de aprendizagem, promovendo um uso de língua significativo para o aluno. Dito isso, este visa a ilustrar e explicitar como o conceito de língua em uso pode ser transposto na produção/adaptação de atividades ou materiais didáticos, por meio de comparações retiradas de um trabalho de mestrado que visou à elaboração de um material didático de português para estrangeiros em contexto universitário. Como resultado, será apresentado um checklist com as principais características a serem observadas nesse processo, contribuindo para a formação e para a prática pedagógica desse professor que quer entender na prática como materializar o conceito de língua em uso em atividades.

PALAVRAS-CHAVE: Língua em uso. Português para Falantes de Outras Línguas (PFOL). Produção de material didático.

RESUMEN: Una necesidad real de los profesores de portugués como lengua extranjera, al producir o adaptar actividades y materiales didácticos que se ajusten a una visión de la lengua como práctica social, es la de materializar, en las actividades, sus princípios, de manera que se ajusten a las expectativas de aprendizaje, promoviendo un uso significativo de la lengua. Dicho esto, este artículo pretende ilustrar y explicar cómo el concepto de lengua en uso puede transponerse en la producción/adaptación de actividades o materiales didácticos, mediante comparaciones tomadas de un trabajo de maestría que tuvo como objetivo la elaboración de un material didáctico de portugués para extranjeros en contexto universitario. Como resultado, se presentará un checklist con las principales características a observar en este proceso, contribuyendo a la formación y a la práctica pedagógica del profesor que quiere entender en la práctica cómo materializar el concepto de lengua en uso en las actividades.

PALABRAS CLAVE: Lengua en uso. Portugués para hablantes de otras lenguas. Producción de material didáctico.

${ }^{1}$ Universidade Estadual de Londrina (UEL), Londrina - PR - Brasil. Professor de Português Língua Estrangeira (PPPLE). Mestrado Profissional em Letras Estrangeiras Modernas (UNESP). ORCID: https://orcid.org/00000001-5346-7446.E-mail: dener.martins@live.com 
ABSTRACT: A demand of teachers of Portuguese as a foreign language, when developing or adapting activities and teaching materials that suit the concept of language as a social practice, is to materialize the theoretical principles that underlie this language perspective in teaching activities, so that it can meet learning expectations and provide the students with meaningful language uses. That said, this article aims to illustrate and explain how the concept of language in use can be transposed in the production/adaptation of teaching activities or in teaching materials, through comparisons drawn from a Master's thesis that aimed at developing a teaching material of Portuguese for foreigners in university context. As a result, it will be presented a checklist with the main characteristics to observed in this process, which can contribute to teacher's training and practice, as well as to those who want to understand how to materialize this concept in teaching activities.

KEYWORDS: Language in use. Portuguese for speakers of other languages. Development of teaching materials.

\section{Introdução}

A produção ou a adaptação de material didático de português para estrangeiros passa por demandas de grupos e contextos específicos e requer um olhar atento às necessidades de aprendizagem e ao uso de língua do público-alvo. Para tanto, o conceito de língua adotado pelo professor, por meio de atividades, deverá ser indicado a partir das expectativas de aprendizagem do aluno, contribuindo para os fins de aprendizagem previstos. Nesse sentido, no que se refere ao ensino de português para estrangeiros em que o objetivo é promover a aprendizagem da língua por meio de interações linguístico-culturais significativas, é preciso que as atividades propostas no material convirjam com uma concepção de língua como prática social, uma vez que é a partir dessa perspectiva que é possível compreender o uso da língua não como um mero instrumento de comunicação, mas como um fenômeno sociocultural que possibilita a interação e uma ação efetiva no mundo.

Partindo da intenção de se adotar uma concepção de língua como prática social em sua prática pedagógica, o professor de português para estrangeiros, a fim de atender a demandas específicas de ensino, aprendizagem e avaliação, vê-se na necessidade de produzir ou adaptar recursos educacionais ou materiais didáticos, uma vez que diferentes realidades de ensino pressupõem diferentes práticas pedagógicas para atingir diferentes objetivos, o que, em última instância, exige que o material didático seja reconfigurado à medida que as necessidades de aprendizagem dos alunos se impõem. Em outras palavras, a turma de português língua de acolhimento, por exemplo, possui demandas de aprendizagem diferentes das da turma de português língua de herança, de modo que o professor atue efetivamente na (re)construção de seu material. 
No entanto, para além da dificuldade de se encontrar no mercado materiais didáticos de português para estrangeiros sob uma abordagem de língua como prática social e sob uma perspectiva intercultural, o professor também encontra dificuldade na própria produção e adaptação de materiais didáticos para esses fins, tendo em vista que

A produção e a escolha de materiais didáticos não se constituem uma tarefa fácil, em especial quando pensamos língua como prática social com to da a sua complexidade e dinamismo. É um exercício contínuo que envolve pôr de lado construtos teóricos consolidados ao longo da vida acadêmica e profissional dos professores de línguas (REIS, 2015, p. 72).

Nesse sentido, Reis (2015) chama a atenção para o papel da compreensão de língua que o professor deverá ter sobre a concepção de língua para os fins de aprendizagem desejados, de modo que esse entendimento possa contribuir tanto para o "despertar da inspiração de novas ideias e práticas de ensino quanto para fazer as adaptações necessárias a partir da reflexão sobre os princípios teórico-metodológicos que orientam o processo de ensino-aprendizagem" (REIS, 2015, p. 13). Dessa forma,

[...] tudo que o professor é e faz deve estar coerente com a abordagem que decide adotar, que ele não pode apenas seguir sua trajetória de en sino sem originalidade ou se apoiar nos livros-texto que lhe são oferecidos destituídos de uma capacidade reflexiva e decisória e sem força criativa. É pre ciso criar, é preciso adaptar-se, é preciso mudar e reinventar (REIS, 2015, p. 40).

Como forma de contribuir para essa demanda de professores, o Portal do Professor de Português Língua Estrangeira (PPPLE), uma plataforma multilateral de gerenciamento da língua portuguesa, disponibiliza recursos didáticos para o ensino e a aprendizagem de português, podendo ser adaptados e atualizados a depender das necessidades dos alunos, o que traz à baila o conceito de Recurso Educacional Aberto (REA), que são recursos de ensino, aprendizagem e pesquisa em domínio público ou que possuem uma licença de propriedade intelectual que permita uso e adaptação.

Portanto, é inegável a contribuição do Portal, haja vista que dispõe de unidades didáticas elaboradas por professores, que, cientes das necessidades e das realidades de seus alunos, tendem a focar em conteúdos menos gerais. Além disso, a plataforma é fundamentada sob a égide da concepção de língua em uso e sob uma perspectiva pluricêntrica de língua, o que permite transitar pelas diferentes linguagens dos países da comunidade lusófona.

Uma vez explanado o motivo pelo qual o professor de português para estrangeiros busca produzir e adaptar materiais didáticos e atividades, este artigo se apresenta com o objetivo de ilustrar e explicitar como o conceito de língua em uso pode ser transposto na 
produção/adaptação de atividades ou materiais didáticos, por meio de comparações retiradas de um trabalho de mestrado que visou à elaboração de um material didático de português para estrangeiros em contexto universitário. Com isso, este trabalho busca contribuir com a formação e com a prática pedagógica desse professor que quer entender na prática como materializar o conceito de língua em uso na elaboração/adaptação de atividades, sejam elas as unidades didáticas do Portal, ou quaisquer outros recursos de ensino e aprendizagem.

Para tanto, este artigo definirá, inicialmente, o conceito de língua em uso, de modo que, na sequência, sejam abordados os princípios que o subjazem, seguidos de exemplos e comparações de atividades, destacando como as primeiras versões de determinadas atividades foram modificadas no decorrer de sua elaboração, com o intuito de adequá-las à concepção de língua em uso, e, consequentemente, ilustrando ao professor os passos importantes para tal. Esse movimento de comparação de atividades é fruto do trabalho desenvolvido no âmbito do programa de Mestrado Profissional em Letras Estrangeiras Modernas (MEPLEM), pela Universidade Estadual de Londrina (UEL). O trabalho intitulado "Português - Universidades: material didático de português para estrangeiros em contexto universitário" teve como objetivo elaborar, apresentar e descrever um material didático de português para estrangeiros em contexto universitário brasileiro, além de elucidar os princípios teóricos que fundamentam suas atividades. Por fim, é apresentado um checklist que sintetiza algumas características importantes que podem constituir uma atividade baseada na concepção de língua em uso.

A concepção de língua em uso, ou de língua como prática social, considera que a língua é um encontro interacional "crucialmente marcado pelo mundo social que o envolve: pela instituição, pela cultura e pela história. Isso quer dizer que os eventos interacionais não

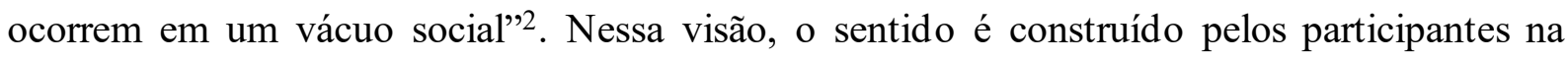
interação de modo dialógico, de maneira que a linguagem é marcada pela interação social, e a língua, por um conjunto de usos convencionados e sócio-historicamente situados. Para o ensino de línguas, essa concepção se manifesta quando as estruturas gramaticais deixam de ter um papel protagonista na aprendizagem e passam a estar a serviço do uso. Em outras palavras, “não se trata mais de aprender uma língua para dela se apropriar, mas de usá-la e, usando-a, aprendê-la" (GERALDI, 2002, p. 53).

Dessa forma, a língua, por ser dialógica, sócio-histórica e culturalmente marcada, manifesta-se de forma indissociável da cultura, sendo apresentada ao alunato por meio de usos de línguas e textos autênticos que circulam no seu espaço de convivência e interação,

${ }^{2}$ Disponível em: http://ppple.org/conversa. Acesso em: 21 jun. 2021. 
visando a alcançar níveis mais altos de proficiência em língua portuguesa, com propósitos específicos. Essa relação não hierárquica entre esses princípios pode ser representada na figura a seguir:

Figura 1 - Representação do conceito de Língua em Uso

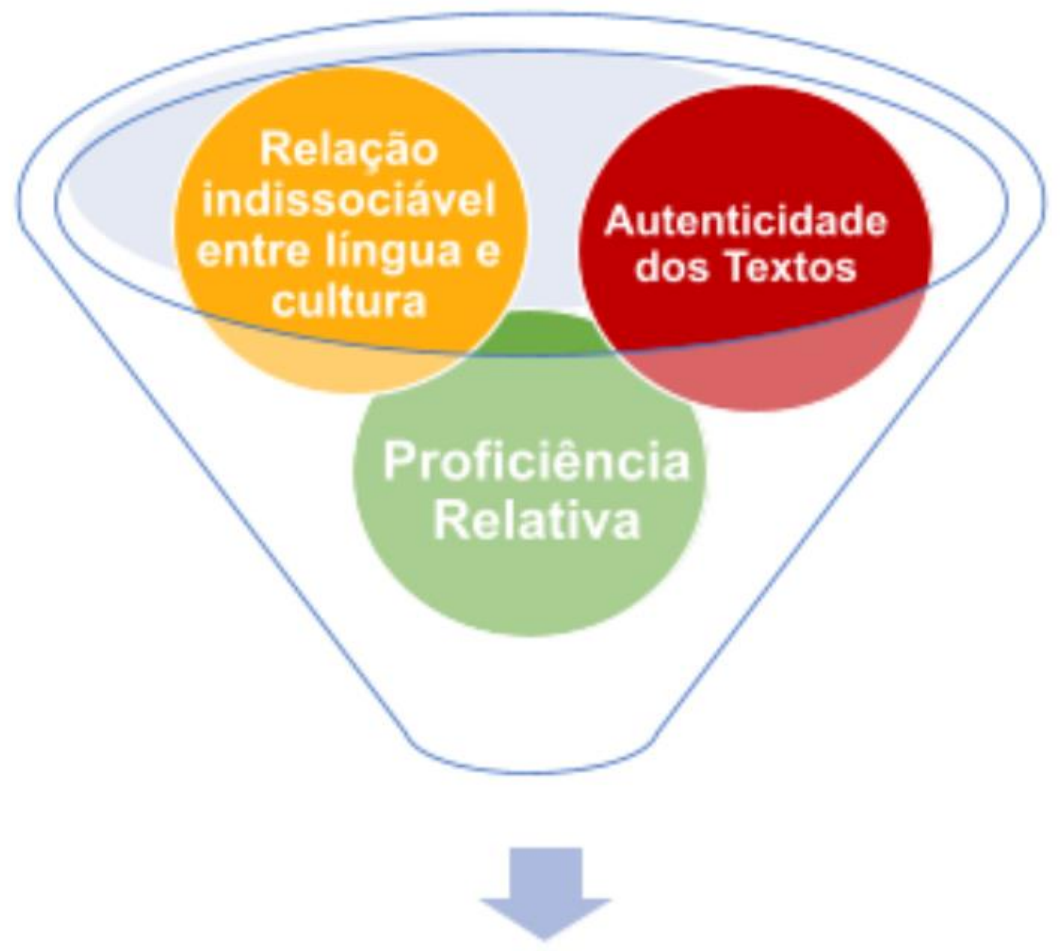

\section{Língua em Uso}

Fonte: Acervo do autor

Portanto, a partir da figura, é possível perceber que a concepção de língua em uso: 1. Almeja subsidiar a prática social e a interação em sociedade; 2 . Prioriza a aprendizagem por meio de situações de comunicação e interação contextualizadas, socialmente e culturalmente significativas e com propósitos bem definidos, o que justifica o uso de textos autênticos que circulam no contexto de vida do aluno; 3. Permite, por fim, dar luz ao conceito de proficiência relativa, o que implica considerar, para fins de uso de língua e avaliação, todos os elementos envolvidos na situação de comunicação, como quem fala, o que fala, para quem, quando, onde, por que e para quê. As figuras a seguir foram selecionadas com o intuito de elucidar o movimento feito pelo autor do material para ajustar as atividades que se baseavam, em um primeiro momento, em uma concepção de língua como estrutura, para então, aproximá-las de uma concepção de língua como prática social/língua em uso, observando os três princípios já elucidados. Sendo assim, a Figura 2 é o primeiro exemplo: 
Figura 2 - Primeira versão da Atividade 7 da seção "Universidade em Foco"

b) A partir das respostas apresentadas, formule perguntas adequadas.

P:

R: Para realizar mobilidade internacional com bolsa, o aluno deve acompanhar os editais ofertados por diversas instituições. Parar fazer mobilidade internacional sem bolsa, o aluno deve procurar a Assessoria de Relações Internacionais e Interinstitucionais (ARII).

P:

R: A revalidação de diploma de graduação e pós-graduação deve ser feita diretamente na Plataforma Carolina Bori, a qualquer tempo. No entanto, o sistema somente dará prosseguimento caso haja vaga.
P:

R: Trancamento de disciplina é o ato de trancar uma ou mais disciplinas durante um semestre. 0 trancamento de disciplinas é feito por meio do Portal do ECampus e deve ser solicitado de acordo com calendário acadêmico.

P:

R: Por meio do Portal Ecampus é possível obter diversos tipos de declarações. Situações mais específicas devem ser enviadas à Coordenação de Orientação Acadêmcica.

P:

R: A Solicitação de matrícula para curso de férias deverá ser realizada diretamente no Portal Ecampus.

Fonte: Acervo do autor

Nessa atividade, o comando a ser executado pelo aluno é formular perguntas adequadas, de acordo com respostas previamente apresentadas. Essa atividade não considera a situação de uso da língua, pois solicita que se façam perguntas sem um propósito e sem um interlocutor contextualmente marcado, o que não confere um uso real de comunicação, mas um exercício meramente linguístico e descontextualizado, tendo em vista que, no cotidiano, os falantes não formulam perguntas de forma despropositada, sem um interlocutor e sem um suporte real de comunicação, a partir de respostas pré-formuladas.

$\mathrm{O}$ conceito de língua em uso foi materializado na atividade, o que resultou na atividade da Figura 3: 
Figura 3 - Versão final da Atividade 7 da seção "Universidade em Foco"

b) Você tem dúvidas quanto aos procedimentos necessários sobre as situações acadêmicas abaixo e não encontra essas respostas no FAQ da sua univerisdade no Brasil. Você entrará em contato com a secretaria por email e perguntará como e onde deverá executar essas ações.
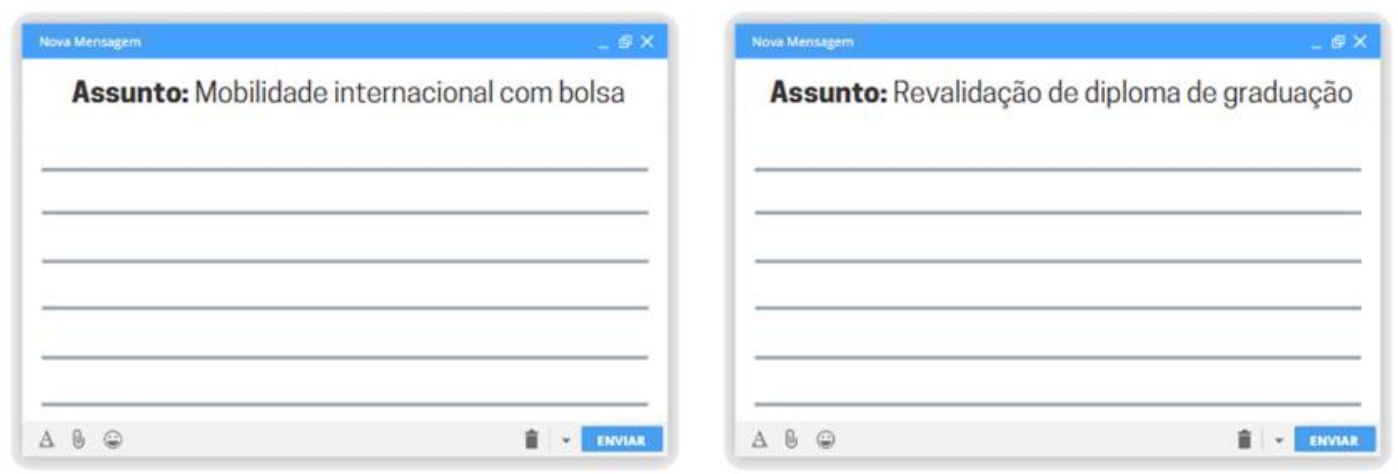

Fonte: Acervo do autor

A atividade da Figura 3 demonstra que o aluno, a fim de tirar dúvidas sobre procedimentos acadêmicos (propósito), em razão das suas dúvidas quanto a procedimentos sobre situações acadêmicas e em razão do fato de não encontrar suas respectivas respostas no FAQ da instituição (motivo), deverá fazer perguntas sobre situações acadêmicas (prática social) à pró-reitoria da sua instituição (interlocutor), por e-mail (suporte). Dessa forma, não deve ser o enunciado da atividade a exigir que o aluno crie uma pergunta, mas o próprio uso da língua contextualizado e com um propósito determinado. Portanto, trata-se de uma atividade mais bem contextualizada e mais significativa para o aluno, o que fornece mais subsídios para que ele possa executá-la com precisão.

Vejamos agora uma outra comparação, em que seja explicitado o papel do suporte real de interação e do uso de materiais autênticos na elaboração de atividades:

Figura 4 - Primeira versão da atividade da seção "Fazendo Acontecer"

Um amigo do seu país está interessado em estudar na sua universidade do Brasil. Ele pergunta sobre o seu curso: duração, o que é exigido, horário das aulas e grau acadêmico. Em folha separada, dê um retorno respondendo-lhe.

Fonte: Acervo do autor

Essa primeira versão de atividade de produção de texto solicita que o aluno escreva, em folha separada, uma resposta à pergunta apresentada, sem definir, contudo, um gênero ou 
um suporte real pertinente aos fins de comunicação propostos, em que a mensagem se concretizará. No cotidiano, os falantes da língua não se comunicam em "folha separada", justamente por não se tratar de um suporte autêntico. Além disso, alguns aspectos contextuais, tais como onde, quando, como e por que, podem não estar bem definidos, o que criaria à comunicação lacunas discursivas, sem um uso real de língua como prática social. Sendo assim, por não apresentar a mobilização de alguns princípios da referida concepção de língua, essa atividade foi reformulada como apresentada na Figura 5:

Figura 5 - Versão final da atividade da seção "Fazendo Acontecer"
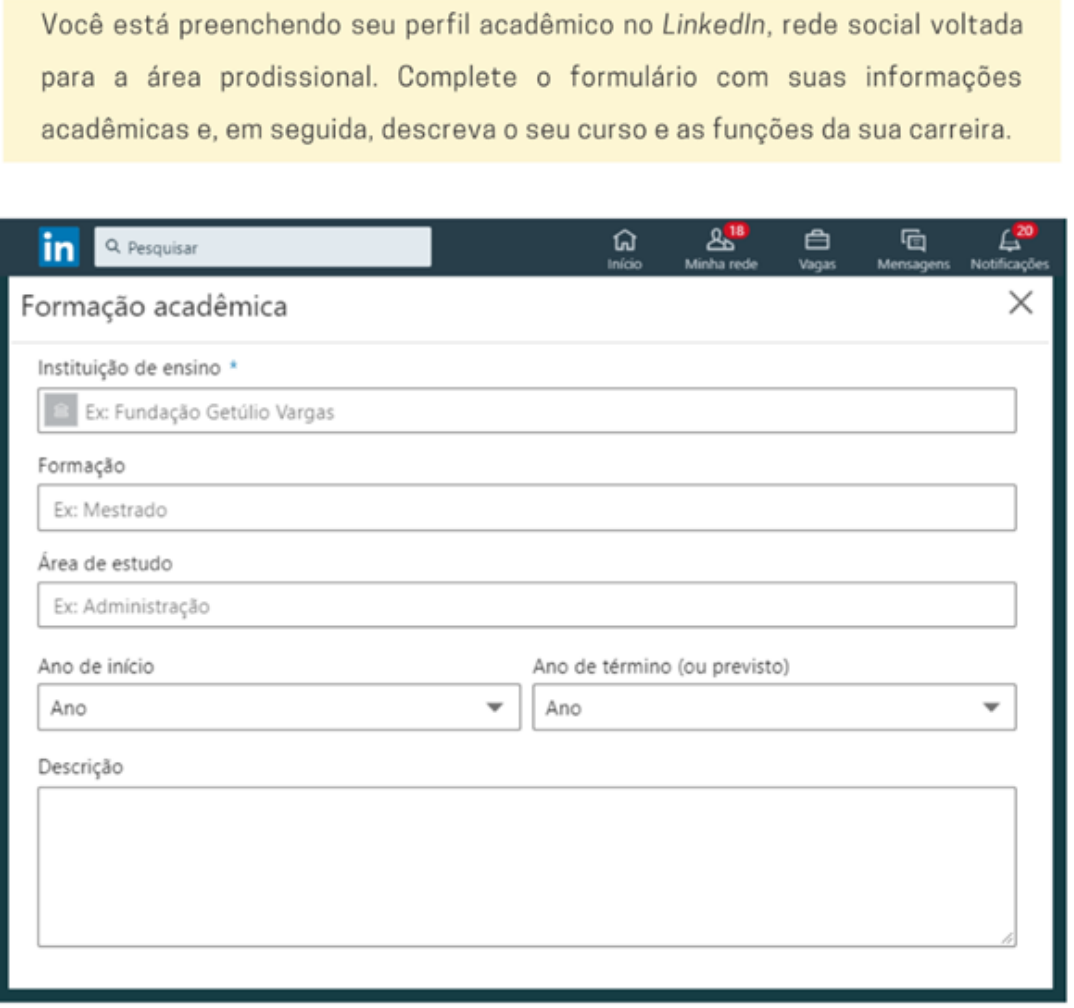

Fonte: Acervo do autor

Nessa atividade, o uso de material autêntico (rede social LinkedIn) e o suporte real de comunicação (página de preenchimento de formação acadêmica) fazem com que o propósito da atividade (falar sobre sua formação) tenha mais significado para sua vida acadêmica. Além disso, o próprio suporte sugere quem serão os agentes da comunicação (amigos, empresas, recrutadores), bem como os aspectos contextuais da interação. Isso significa dizer que, a partir da autenticidade desse texto, as particularidades específicas do gênero serão consideradas, como linguísticas (léxico e estrutura), discursivas (coesão e coerência) e contextuais (interlocutor, motivo, propósito). Nesse sentido, o aluno é levado a (re)conhecer e a fazer uma 
“interpretação do que é dito, quando, por quem, para quem e para quê"3, calibrando o uso de diferentes registros linguísticos-culturais e graus de formalidade, o que implica na forma com que será feita a avaliação dessa produção textual, de modo que o aluno possa ser avaliado e possa ajustar, coerentemente, o uso e as nuances dos aspectos linguísticos, discursivos e contextuais com a situação de uso de língua em questão. Ao fazê-lo, o aluno demonstrará ser proficiente nessa situação de uso. Dessa forma, ser proficiente é

[...] ser capaz de usar a língua adequadamente com propósitos sociais (CLARK, 1996; CONSELHO da EUROPA, 2001) ou ser capaz de u sar "a língua para desempenhar ações no mundo" (BRASIL, 2011, p. 4). Nesse caso, portanto, não falamos de uma proficiência única, mas de "proficiências" ou níveis de proficiência distintos, definidos a partir da reflexão sobre a natureza da linguagem em situações variadas de uso da língua (PPLE, s/a).

Isso remonta o conceito de proficiência relativa, que preconiza que não há uma única proficiência, mas distintas proficiências que se interrelacionam. Diferentemente da proficiência monolítica ou absoluta, que parte de uma perspectiva estruturalista, a proficiência relativa leva em consideração os diversos contextos e propósitos de usos de língua. Assim, temos diferentes "proficiências" e diferentes níveis de proficiência, de acordo com determinada situação de uso para determinado fim (MENDES; FURTOSO, 2018). Desse modo, em vez de dizer que o aluno é proficiente em português, é mais adequado dizer que o aluno é proficiente em português para desempenhar determinada ação com um determinado fim (SCARAMUCCI, 2000).

Quanto à cultura, a atividade a seguir (Figura 6), nas perguntas $a$ e $b$, explora vocabulário e conceitos que circulam no contexto universitário, promovendo o contato com aspectos linguístico-culturais para que o aluno possa (re)conhecer o estilo de vida universitário no Brasil:

3 Disponível em: http://ppple.org/conversa. Acesso em: 21 jun. 2021. 
Figura 6 - Primeira versão da Atividade 1 da seção "Universidade em Foco"

a) Ligue as palavras com as imagens.

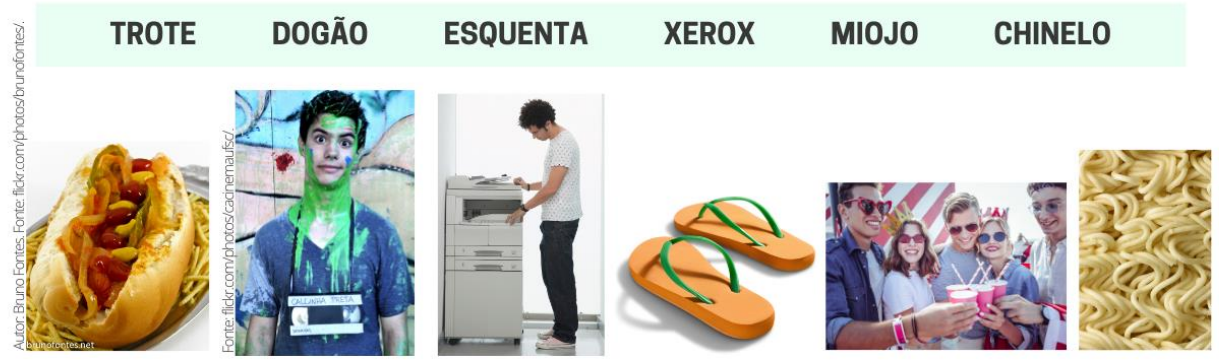

b) 0 texto aborda palavras comuns à vida do universitário. Complete o quadro de definição com as palavras apropriadas.

0 _._._._é a sigla para Trabalho de Conclusão de Curso. Ao final do curso de graduação, os alunos devem defender seu TCC.

\begin{tabular}{|c|c|}
\hline ABNT & $\begin{array}{l}0 \text {....... é o momento que os estudantes bebem em outro lugar } \\
\text { antes de ir à uma festa. }\end{array}$ \\
\hline TCC & $\begin{array}{l}0 \text { _...- é como informalmente alguns brasileiros se referem ao } \\
\text { cachorro-quente ou hot dog. }\end{array}$ \\
\hline $\begin{array}{l}\text { ESQUENTA } \\
\text { TROTE }\end{array}$ & $\begin{array}{l}\text { ser de mal gosto, como pedir dinheiro no farol, raspar os cabelos e banhar- } \\
\text { se de tinta. Mais recentemente, essa atividade de recpeção aos calouros } \\
\text { tem se caraterizado como uma solidária. }\end{array}$ \\
\hline DOGÃO & $\begin{array}{l}\text { A _._é a sigla para Associação Brasileira de Normas Técnicas. } \\
\text { Trabalhos acadêmicos e artigos científicos devem obedecer a essa norma. }\end{array}$ \\
\hline CALOURO/A & $\begin{array}{l}\text { Na faculdade, o/a } \\
\text { Também pode ser chamado informalmente de bixo ou bixete. }\end{array}$ \\
\hline VETERANO/A & $\begin{array}{l}\text { reprovada na faculdade. } \\
\text { réna de "dependência", referindo-se à disciplina }\end{array}$ \\
\hline & $\begin{array}{l}\text { Na faculdade, o/a _.____._e é o aluno que já passou do segundo ano de } \\
\text { faculdade. }\end{array}$ \\
\hline
\end{tabular}

Fonte: Acervo do autor

Contudo, a atividade, tal como foi proposta, teria o potencial de melhor explorar alguns aspectos culturais sobre o estilo de vida universitário, dado o fato de que se trata de experiências e formas de encarar a realidade potencialmente diversificadas e ricas, o que abriu espaço para a adição das seguintes perguntas: 
Figura 7 - Perguntas $c$, $d$, e e $f$ da Atividade 1 da seção "Universidade em Foco"

c) Você reconhece ou já presenciou algumas dessas situações do texto na universidade no Brasil? Quais?

d) Você se identifica com alguma dessas situações? Quais?

e) Quais dessas situações do texto mais chamou a sua atenção? Por quê?

f) Quais dessas situações você concorda ou discorda? Por quê?

Fonte: Acervo do autor

Essas perguntas, além de auxiliarem na compreensão dos conceitos, revelam um potencial de mobilizar aspectos culturais presentes no estilo de vida universitário. Uma vez munido de um arcabouço linguístico-cultural, o aluno é convidado a refletir sobre as diferentes formas de ver o mundo, de modo que consiga enxergar e compreender diferentes realidades de forma mais ampliada, o que também promove um diálogo crítico e esclarecedor sobre como e por que as coisas acontecem naquele espaço e daquele jeito. Assim, a língua se apresenta como uma forma de representação de percepções e de valores culturais, não sendo possível identificar o limite entre língua e cultura. Com isso, na perspectiva de língua em uso, a língua não é concebida tão somente como um instrumento de comunicação, mas como uma forma de identificação social e cultural. Portanto, essa indissociabilidade entre língua e cultura pode ser entendida como "uma lente através da qual enxergamos a realidade que nos circunda" (MENDES, 2012, p. 25). Dessa forma,

[...] ao estruturar os nossos pensamentos e ações, ela faz a mediação entre as nossas experiências e a do outro com o qual interagimos socialmente através da linguagem, auxiliando-nos a organizar o mundo à nossa volta. Nesse sentido, a cultura não está antes nem depois da língua, nem uma dentro da outra, elas estão no mesmo lugar (MENDES, 2012, p. 25).

Portanto, para Mendes (2010), e levando em consideração a língua como prática social, não se pode desvincular a língua dos aspectos socioculturais que circundam seu uso, uma vez que, ao usar a língua, o indivíduo age socioculturalmente por meio dela. Além disso, Mendes (2007) ainda destaca que, na sala de aula, essa perspectiva requer um diálogo entre culturas por meio de contrastes culturais (MENDES, 2007), visando à naturalização dos estranhamentos, "na busca de um conhecimento crítico do outro e de si mesmo, na busca da convivência harmoniosa e de respeito das diferenças" (MAIOR; SOUZA, 2018, p. 99). Nesse sentido, as perguntas que foram adicionadas à atividade têm o potencial de não só explorar aspectos culturais do estilo de vida universitário brasileiro, como também de promover o 
contrastante, a valorização e o respeito entre as diferentes formas de ver e encarar diferentes realidades.

Como forma de sintetizar o movimento feito pelo autor na busca de se materializar os princípios que subjazem o conceito de língua em uso, será apresentado, a seguir, um checklist com um passo a passo do que o professor poderá se atentar quando elaborar ou adaptar atividades ou materiais didáticos para fins de ensino baseado na perspectiva de língua em uso:

- Criar uma tarefa pertinente e significativa à vida do aluno (o quê).

- Explicitar um propósito significativo para a tarefa (para quê).

- Explicitar um motivo para a execução da tarefa (por quê).

- Explicitar os interlocutores envolvidos na tarefa (quem).

- Explicitar um suporte real e autêntico de interação (onde).

- Explicitar de que forma o aluno deverá executar a tarefa (como).

- Explorar aspectos linguístico-culturais.

- Promover o contraste, o respeito mútuo e a opinião crítico-reflexiva sobre aspectos e valores culturais.

Esse checklist sintetiza algumas características importantes que podem constituir uma atividade baseada na concepção de língua em uso. Vale ressaltar, contudo, que são os objetivos de ensino e aprendizagem pré-concebidos que vão indicar quais desses aspectos poderão fazer parte da atividade em um grau maior ou menor. Além disso, é a partir da tarefa, dos propósitos de uso de língua e das particularidades do gênero que serão definidos, mobilizados e calibrados os aspectos linguísticos, discursivos e contextuais, de modo que o aluno possa adequá-los à situação de uso de língua em questão, e o professor avaliá-lo sob a ótica da proficiência relativa.

\section{Considerações finais}

Atender a diferentes demandas de ensino por meio da elaboração ou da adaptação de atividades e de materiais didáticos, considerando os propósitos e as expectativas de aprendizagem da turma ou do aluno, é um desafio que exige do professor não só o reconhecimento das necessidades de aprendizagem do contexto, mas também a escolha de qual é a melhor concepção de língua que poderia facilitar o alcance dos objetivos de ensino e aprendizagem. Para tanto, é preciso que o professor conheça qual é a concepção de língua que se quer adotar e como adotá-la, e, ao fazê-lo, garantir que seus princípios possam ser refletidos no material didático utilizado. 
No caso de os objetivos de ensino e aprendizagem indicarem a necessidade de se promover, dentro do contexto de ensino, interações e usos de língua significativos, a concepção de língua em uso se adequa a esses propósitos, de modo que o professor precisa conhecer os pilares que a fundamentam, bem como materializá-los quando elaborar ou adaptar atividades ou materiais didáticos para a turma. E é nesse sentido que este artigo se apresenta, na busca de contribuir com a formação e com a prática pedagógica desse professor que quer entender na prática como materializar o conceito de língua em uso, bem como seus princípios, na elaboração/adaptação de atividades, seja a adaptação de materiais didáticos do mercado, seja a adaptação de unidades didáticas do PPPLE.

O resultado é um checklist que sintetiza brevemente as principais características que o professor de português para estrangeiros poderá observar quando elaborar ou adaptar atividades baseadas na concepção de língua em uso, o que também tem potencial de ajudá-lo na sua prática pedagógica ao tentar cruzar as necessidades de aprendizagem do aluno com a atividade ideal que cumpra tais objetivos.

\section{REFERÊNCIAS}

BRASIL. Ministério da Educação e Cultura. Instituto Nacional de Estudos e Pesquisas Educacionais Anísio Teixeira. Manual do Examinando do Exame Celpe-Bras. Brasília, DF, 2011.

CLARK, H. Language use. In: CLARK, H. (org.). Using language. Cambridge: Cambridge University Press, 1996, p. 3-25.

\section{CONSELHO DA EUROPA. Quadro Comum Europeu De Referência Para Idiomas:}

Aprendizagem, Ensino e Avaliação. Lisboa, Portugal: ASA Editores, 2001.

GERALDI, J. W. Linguagem e ensino: exercícios de militância e divulgação. Campinas: Mercado de Letras, 2002.

MAIOR, R. C. S.; SOUZA, M. V. O ensino de português para estrangeiros numa perspectiva dialógica e as construções de ethos neste contexto. Revista Horizontes de Linguistica Aplicada, v. 17, n. 2, dez. 2018, p. 23-38.

MENDES, E. A Perspectiva Intercultural no Ensino de Línguas: uma relação "entreculturas". In: ALVAREZ, M. L. O.; SILVA, K.A. da (org.). Linguística Aplicada: múltiplos olhares. Campinas, SP: Pontes, 2007. p. 119-154.

MENDES, E. Por que ensinar língua como cultura? In: SANTOS, P.; ALVAREZ, M. L. O. Língua e cultura no contexto de Português Língua Estrangeira. Campinas, SP: Pontes, 2010, p. 53-77. 
MENDES, E. Vidas em Português: perspectiva culturais e identitárias em contexto de português língua de herança (PLH). Revista do Instituto Internacional da Língua Portuguesa, Cabo Verde, IILP, 2012.

MENDES, E.; FURTOSO, V. B. Orientações do PPPLE para a produção de materiais e recursos didáticos: uma perspectiva plural para aprender, avaliar e ensinar em PLE/PLNM. Revista Platô, v. 4, n. 7, p. 20-29, 2018.

PPLE. Portal do Professor de Português Língua Estrangeira. Conversa com o Professor. s/a. Disponível em: http://ppple.org/conversa. Acesso em: 21 jun. 2021.

REIS, L. M. Através do espelho: o portal do professor de português língua estrangeira/ língua não materna (PPPLE) sob uma ótica pluricêntrica e intercultural. 2015. $121 \mathrm{f}$. Dissertação (Mestrado em Língua e Cultura) - Instituto de Letras, Universidade Federal da Bahia, Salvad or, 2015.

SCARAMUCCI, M. V. R. Proficiência em LE: considerações terminológicas e conceituais. Trabalhos em Lingüística Aplicada, Campinas, v. 36, p. 11-22, 2000.

\section{Como referenciar este artigo}

OLIVEIRA, D. M. A A materialização do conceito de língua em uso na produção de atividades para o ensino de português para estrangeiros. Rev. EntreLínguas, Araraquara, v. 7, n. esp. 6, e021141, dez. 2021. e-ISSN: 2447-3529. DOI: https://doi.org/10.29051/el.v7iesp.6.15408

Submetido em: 30/08/2021

Revisões requeridas em: $14 / 10 / 2021$

Aprovado em: 28/11/2021

Publicado: 28/12/2021 